\title{
On the determination of gravity wave momentum flux from GPS radio occultation data
}

\author{
A. Faber ${ }^{1,2}$, P. Llamedo ${ }^{3}$, T. Schmidt ${ }^{1}$, A. de la Torre ${ }^{3}$, and J. Wickert ${ }^{1}$ \\ ${ }^{1}$ Department 1, Geodesy and Remote Sensing, GFZ German Research Centre for Geosciences, Potsdam, Germany \\ ${ }^{2}$ Institute for Space Sciences, Freie Universität Berlin, Berlin, Germany \\ ${ }^{3}$ Facultad de Ingeniería, Universidad Austral, Buenos Aires, Argentina
}

Correspondence to: A. Faber (antonia.faber@gfz-potsdam.de)

Received: 7 December 2012 - Published in Atmos. Meas. Tech. Discuss.: 22 March 2013

Revised: 14 October 2013 - Accepted: 21 October 2013 - Published: 20 November 2013

\begin{abstract}
Global Positioning System (GPS) radio occultation (RO) is a well-established technique for obtaining global gravity wave (GW) information. RO uses GPS signals received by low Earth-orbiting satellites for atmospheric limb sounding. Temperature profiles are derived with high vertical resolution and provide a global coverage under any weather conditions, offering the possibility of global monitoring of the vertical temperature structure and atmospheric wave parameters. The six-satellite constellation COSMIC/FORMOSAT- 3 delivers approximately 2000 temperature profiles daily. In this study, we use a method to obtain global distributions of horizontal gravity wave wavelengths, to be applied in the determination of the vertical flux of horizontal momentum transported by gravity waves. Here, a method for the determination of the real horizontal wavelength from three vertical profiles is applied to the COSMIC data. The horizontal and vertical wavelength, the specific potential energy $\left(E_{\mathrm{p}}\right)$, and the vertical flux of horizontal momentum (MF) are calculated and their global distribution is discussed.
\end{abstract}

\section{Introduction}

The important role of gravity waves (GWs) for atmospheric circulation and energy transport is already recognized (Nappo, 2002; Fritts and Alexander, 2003; Sutherland, 2010; Alexander et al., 2010). Recent developments in gravity wave effects and momentum flux analysis are summarized by Alexander et al. (2010). The variety of atmospheric sounding instruments, designed to detect GWs and find answers to related queries, has increased over the last decades. Radiosonde soundings and ground-based measurements, as well as air- and spaceborne measurements, cover a large range of measuring possibilities. The two major measuring techniques for satellite measurements are (i) nadirscanning instruments, like the Advanced Microwave Sounding Unit (AMSU) (Eckermann et al., 2006) and the Atmospheric InfraRed Sounder (AIRS) (Hoffmann and Alexander, 2009), and (ii) limb-sounding instruments, like the CRyogenic Infrared Spectrometers and Telescopes for the Atmosphere (CRISTA) (Ern et al., 2004), the HIgh Resolution Dynamics Limb Sounder (HIRDLS), the Sounding of the Atmosphere using Broadband Emission Radiometry (SABER), and the many radio occultation (RO) receivers aboard the different low Earth-orbiting (LEO) satellites like the Constellation Observing System for Meteorology, Ionosphere and Climate (COSMIC) (see Wright et al., 2011). The Global Positioning System (GPS) RO technique provides vertical profiles of atmospheric properties such as refractivity, from which density $(\rho)$, pressure $(P)$, temperature $(T)$, and water vapor pressure $(e)$ are derived. The vertical resolution of RO profiles ranges from $0.1 \mathrm{~km}$ in the lower troposphere to $1.4 \mathrm{~km}$ in the stratosphere (Kursinski et al., 1997). This technique operates under any weather conditions and provides global coverage. However, the sampling in the GPS RO method is more irregular in time and space than the sampling in other techniques. A long-term series of GPS RO measurements is available from the CHAllenging Minisatellite Payload (CHAMP) satellite, which had provided approximately 150 daily profiles between 2001 and 2008 (Wickert et al., 2001; Wickert, 2002). A higher density of data is given by 
COSMIC. The joint Taiwan/US science mission started in April 2006 and delivers 2000 profiles each day (Anthes et al., 2008). RO receivers are also operating aboard other satellites, including the Gravity Recovery And Climate Experiment (GRACE, launched in 2002), or the two radar satellites TerraSAR-X (launched in 2007) and TanDEM-X (launched in 2010). The RO technique has been widely used for GW analysis (see Kuo et al., 2000; de la Torre and Alexander, 2005; Alexander et al., 2008a, b; Horinouchi and Tsuda, 2009; Lin et al., 2010; Wang and Alexander, 2010). As shown by Marquardt and Healy (2005), small-scale fluctuations of dry temperature RO profiles can be interpreted as gravity waves (GWs), when the vertical wavelength is equal or greater than $2 \mathrm{~km}$. When the wavelengths are lower, the fluctuations may be related to noise. To keep the signal-tonoise ratio for the temperature fluctuation above the detection threshold, the analysis should be applied to altitudes lower than $30 \mathrm{~km}$ (Alexander et al., 2008a) or, as suggested by Marquardt and Healy (2005), in the 20-30 km altitude range. The specific potential energy $\left(E_{\mathrm{p}}\right)$ is a parameter for the characterization of gravity wave activity, given by

$$
\begin{aligned}
E_{\mathrm{p}}(z) & =\frac{1}{2}\left(\frac{g}{N_{z}}\right)^{2}\left(\frac{\hat{T}}{\bar{T}}\right)^{2} \\
N_{z}^{2} & =\frac{g}{\bar{T}}\left(\frac{\delta \bar{T}}{\delta z}+\frac{g}{c_{p}}\right),
\end{aligned}
$$

where $N_{z}$ is the Brunt-Väisälä frequency, $g$ is the gravitational acceleration, $c_{p}$ is the isobaric heating capacity, and $\hat{T}$ and $\bar{T}$ are the amplitude and background components of temperature, respectively. The temperature amplitude profile is derived from a wavelet analysis of the temperature fluctuation profile $\left(T^{\prime}\right)$. Unlike planetary waves, small-scale GWs are usually sub-grid scale phenomena or under-resolved in both the horizontal and the vertical in numerical weather prediction models (Alexander et al., 2010). In order to quantify the effect of small-scale GWs alone, it is important to separate these GWs from planetary waves. The GW analysis is based on the extraction of the vertical $T^{\prime}$ contribution. Together with the measuring technique, the background determination sets the range of detectable GWs, even though the amount of planetary waves can not be perfectly extracted. Here, a continuous wavelet transform (CWT) analysis is used for the background determination (see Sect. 2.1).

Ern et al. (2004) introduced a method to derive horizontal wavelength $\left(\lambda_{\mathrm{h}}^{p}\right)$ projected along the line connecting two adjacent $T$ profiles (using CRISTA temperature data) for a given altitude:

$k_{\mathrm{h}}^{p}=\frac{\Delta \phi_{i j}}{\Delta x_{i j}}=\frac{2 \pi}{\lambda_{\mathrm{h}}^{p}}$,

where $\Delta x_{i j}$ is the distance and $\Delta \phi_{i j}$ is the phase shift between the two profiles at a given altitude. To extract the true horizontal wavelength $\left(\lambda_{h}\right)$ of the gravity wave, at least a third $T$ profile (not aligned with the others) is needed. Measurements must be close in time and space in order to provide observations of the same wave packet. Assuming a single prevailing wave within the packet, the absolute value of vertical flux of horizontal momentum (MF) for mid-frequency approximation and is given by

$|\mathrm{MF}|=\rho \frac{\lambda_{\mathrm{v}}}{\lambda_{\mathrm{h}}} E_{\mathrm{p}}$,

where $\lambda_{v}$ is the vertical wavelength. Wang and Alexander (2010) used clusters of three or more RO measurements grouped in $15^{\circ} \times 15^{\circ} \times 4 \mathrm{~h}$ (longitude $\times$ latitude $\times$ time) cells to derive $\lambda_{\mathrm{h}}$ and the MF in the altitude range of $17.5-22.5 \mathrm{~km}$ during December 2006 to February 2007. So carried out, this method represents an overdetermined set of equations which is not optimized. In our paper, we apply the Wang and Alexander (2010) method for deriving $\lambda_{h}$ from multiple profiles, but limit the results to those derived from only 3 profiles, and compute resulting GW parameters at a higher spatial resolution of $5^{\circ} \times 5^{\circ}$ lat./long. Other differences compared to Wang and Alexander (2010) are phase shift $(\Delta \Phi)$ limitations, and restrictions regarding the geometric arrangement of the groupings (see Sects. 3 and 4).

In Sect. 2, the GPS measuring technique and the processing of the data set (Sect. 2.1) is described; Sect. 3 focuses on the determination of the real horizontal wavelength. Section 4 shows sensitivity studies for the determination of $\lambda_{\mathrm{h}}$ and $\lambda_{\mathrm{h}}^{p}$, and Sect. 5 shows the results of two different methods for deriving the horizontal wavelengths. Section 6 presents the global distribution results of the GW parameters.

\section{GPS RO technique}

A GPS receiver on-board a LEO satellite measures the Doppler shift of the dual frequency signal of one of the many GPS satellites rising or setting on the local horizon. The Doppler shift can be converted to the radio wave bending angles from which the atmospheric refractivity is derived. In the neutral atmosphere, the refractivity is further reduced to temperature $(T)$, pressure $(P)$ and electron density in neutral atmosphere profiles (Anthes et al., 2008; Kursinski et al., 1997).

The capability of the RO technique to properly detect GWs depends principally on the relative orientation between the wave fronts and the line-of-sight (LOS) between the GPS and LEO satellites. Wave amplitudes can be better resolved when the fronts are nearly horizontal or when the angle between the LOS and the horizontal component of the wave vector approaches $\pi / 2$ (Alexander et al., 2008a). Short horizontal scale waves have a high probability of being attenuated or not being detected at all. The geometry of gravitywave detection is further explained by Preusse et al. (2009). In contrast to CRISTA, the GPS RO data sets (irrespective of 
which mission) have neither a regular spanned grid on which the measurements are taken, nor an almost constant LOS.

In this work, we use the COSMIC post-processed dry temperature profiles provided by the University Corporation for Atmospheric Research (UCAR) COSMIC Data Analysis and Archival Center (CDAAC) Version 2007.3200 for the global analysis. The dry temperature profiles are provided from near the surface up to $40 \mathrm{~km}$, at $0.1 \mathrm{~km}$ steps.

\subsection{Data processing}

In order to calculate $E_{\mathrm{p}}$, the fluctuation has to be extracted from each $T$ profile. Earlier works (Hocke and Tsuda, 2001; Tsuda et al., 2000, 2004; Baumgaertner and McDonald, 2007; de la Torre et al., 2006a, b; Schmidt et al., 2008) used a vertical filter directly on the $T$ profile. The resulting $T^{\prime}$ profiles $\left(T^{\prime}=T-\bar{T}\right)$ still include longer waves with vertical wavelengths $\left(\lambda_{\mathrm{v}}\right)$ similar to GWs (e.g., Kelvin waves Holton et al., 2001). To exclude planetary and Kelvin wave contribution, a $\bar{T}$ including these waves must be computed. In addition to that, the vertical temperature amplitudes are derived using a wavelet analysis of the fluctuation profile. Following Wang and Alexander $(2009,2010)$, we first binned all $T$ profile data (taking into account a compromise between the resolution that we may obtain and the density of available profiles) into a $10^{\circ} \times 15^{\circ}$ lat./long. field between $9-40 \mathrm{~km}$ with a vertical resolution of $100 \mathrm{~m}$. For the daily binned profiles, a CWT as a function of longitude is performed for each latitude and altitude. This allows one to estimate wave numbers $0-6$ for each longitude. The "large-scale variation", reconstructed by wave numbers $0-6$, is then interpolated back onto the location of the original $T$ profile and subtracted from it. The resulting $T^{\prime}$ represents the wave fluctuations of short scale waves (shorter than wave number 6). For this determination of $\bar{T}$, time variations of large-scale waves within 1 day are not taken into account.

Next, $\lambda_{\mathrm{v}}$ (using a CWT analysis) and $E_{\mathrm{p}}$ (using Eq. 1) can be computed from the $T^{\prime}$ profiles (using the $\hat{T}$ ) in order to be presented as seasonal mean values in a $5^{\circ} \times 5^{\circ}$ resolution. From Eq. (2), $\lambda_{\mathrm{h}}^{p}$ along the line connecting two adjacent $T$ profiles for a given altitude is determined. This method is restricted to pairs of measurements within a small temporal and spatial window (both measurements are supposed to be taken within the same $\pi$-cycle of the wave). To ensure that they come from the same wave packet, the vertical structure of the considered profiles must be similar. For the phase difference determination, it is very important that all the RO profiles are measured with a similar LOS. Ideally, the LOS of all the measurements should be parallel. In addition to that, the geometric configuration between the LOS and the wave propagation direction limits one's capability to see a GW (Alexander et al., 2008a). Using at least three RO measurements (not collinear with each other), we can derive $\lambda_{\mathrm{h}}$ instead of $\lambda_{\mathrm{h}}^{p}$. All RO profiles of these groupings must fulfill strict temporal and spatial restrictions. In this work, the temporal and spatial windows were set to $2 \mathrm{~h}$ and $15^{\circ}$ in all directions. The reason for these parameter settings will be explained in Sect. 4.

Alexander and de la Torre (2010) used a similar method to derive wavelengths in a Cartesian coordinate system from three soundings. They describe that the ideal case would be a perpendicular arrangement between the three soundings; however, the COSMIC constellation does not provide this ideal arrangement.

The six identical COSMIC satellites were launched on one rocket into an orbit of $405 \mathrm{~km}$ and later raised to their final orbit of approximately $800 \mathrm{~km}$. During the COSMIC clustering phase (the first months) several measurements were obtained in a small spatial and temporal window and with similar LOS.

Before this method is applied to the RO data, the relative positioning of pairs of RO profiles with respect to the wave must be taken into account. In a case in which the alignment of one of the pairs is perpendicular to the wave propagation direction, there will not be a phase shift between the different $\hat{T}$ profiles. Those pairs of RO measurements where $\Delta \Phi$ is lower than 0.5 radian $\left(\lambda_{\mathrm{h}}^{p}>10000 \mathrm{~km}\right)$ are not taken into account (see Sect. 4).

From the CWT analysis (using a Morlet wavelet) the dominant $\lambda_{\mathrm{V}}$ at considered altitudes is determined. We treat $\hat{T}$ profiles with a dominant $\lambda_{\mathrm{v}}$ within an interval of $2 \mathrm{~km}$ as belonging to the same wave system. The analyzed vertical wavelength interval ranges between 2 and $12 \mathrm{~km}$; therefore, the chosen vertical wavelength window is rather small. Ern et al. (2004) used a window of $6 \mathrm{~km}$ for the CRISTA-2 data set. In Fig. 1a, two RO temperature profiles $\left(T_{1,2}\right)$ are displayed for the altitude range between $20-30 \mathrm{~km}$. Their global (for the entire altitude range) dominant $\left(\lambda_{\mathrm{V}}\right)$ for $T_{1}$ is shown in Fig. 1b, and for $T_{2}$ Fig. 1c. The phase shift between these profiles was determined from the cross-wavelet spectrum, and is shown for the dominant $\lambda_{v}$ at each altitude in Fig. 1d. The phase shift has been determined in the same way at each altitude for all pairs of $T$ profiles. Once the phase shift and the distances are known, $k_{\mathrm{h}}^{p}$ can be derived for all altitudes.

\section{Horizontal wave parameters}

For the determination of MF, we need $k_{\mathrm{h}}$ instead of $k_{\mathrm{h}}^{p}$. As mentioned before, a third measurement is needed to derive $k_{\mathrm{h}}$. For a detailed explanation we take a look at Fig. 2, starting with Fig. 2a. Two vertical $T^{\prime}$ RO profiles ( $T^{\prime} 1$ in brown and $T^{\prime} 2$ in blue), separated by the horizontal distance $\Delta x$, are displayed. The $\Delta \Phi$ between these measurements is derived from a cross-wavelet analysis for each altitude. Figure $2 \mathrm{~b}$ shows the derived $k_{\mathrm{h}}^{p}$ (orange arrow) from three $\hat{T}$ measurements at one altitude and the true $k_{\mathrm{h}}$ (green arrow). The dotted lines are the corresponding $\lambda_{\mathrm{h}}^{p}$ (orange line) and $\lambda_{\mathrm{h}}$ (green line). When using these three measurements, $k_{\mathrm{h}}$ can be derived by 

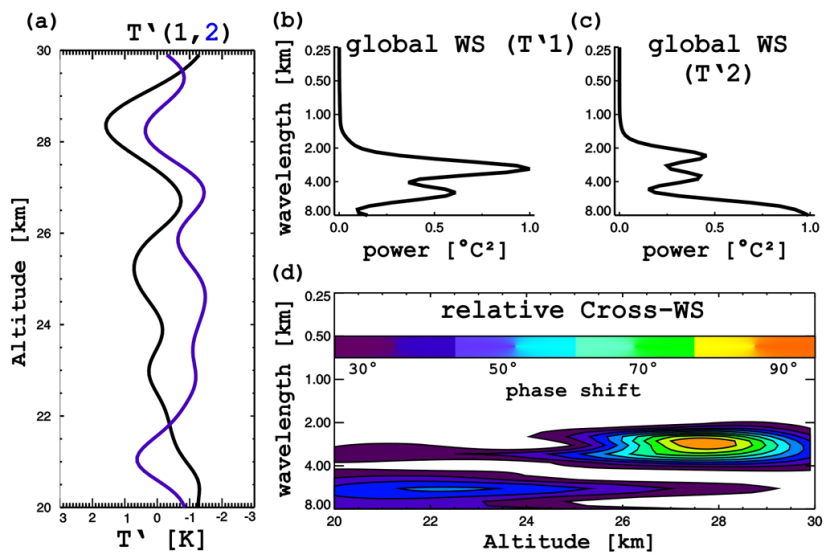

Fig. 1. Two RO temperature fluctuation $\left(T^{\prime}\right)$ profiles (a) and their corresponding horizontal wavelength $\left(\lambda_{\mathrm{V}}\right)$ spectra $(\mathbf{b}, \mathbf{c})$. The crosswavelet shows the phase shift at each altitude (d), for the dominant vertical wavelength $\left(\lambda_{\mathrm{V}}\right)$.

$$
\begin{aligned}
\Delta \phi_{i j} & =k\left(x_{i}-x_{j}\right)+l\left(y_{i}-y_{j}\right) \quad i, j=1,2,3 \\
k_{\mathrm{h}} & =\sqrt{\left(k^{2}+l^{2}\right)},
\end{aligned}
$$

where $(k, l)$ are the horizontal components of the wave number vector, and $\left(x_{i, j}, y_{i, j}\right)$ are the RO coordinates at given altitude. This equation is also the basis of the least square fitting method which Wang and Alexander (2010) used to determine the horizontal wavelength. Here, derivation of the horizontal wavelength is always carried out using only three measurements, thus avoiding an overdetermination of the problem and optimizing the limited information available (given the considerably sparse data density). $\Delta \Phi_{i j}$ is derived from cross-wavelet analysis for each pair of $T^{\prime}$ profiles (Fig. 2c). Since this is an over-determined problem, there can be more than one result. The reference point (RP) from which this system of equations is solved plays an important role. As shown in Fig. 2c, the location of $\left(x_{i j}, y_{i j}\right)$ and the distances between the points $\left(\Delta x_{i j}\right)$ are known, as are the phase shifts $\left(\Delta \Phi_{i j}\right)$ between each measurement pair. When using P1 as RP, Eq. (4) is solved using two equations for $\Delta x_{i j}: \Delta x_{12}$ and $\Delta x_{13}$. In a similar way, when using $\mathrm{P} 2$ as $\mathrm{RP}, \Delta x_{i j}$ are $\Delta x_{12}$ and $\Delta x_{23}$; and for P3 as RP, $\Delta x_{i j}$ are $\Delta x_{13}$ and $\Delta x_{23}$. When the equations are solved for each RP, three $k_{\mathrm{h}}$ are derived. As displayed in Fig. 2d, at least two identical $k_{\mathrm{h}}$ (green arrows) and a third $k_{\mathrm{h}}$ (purple arrow) are derived. All three displayed green arrows are identical in length and orientation. The two starting in P1 and P3 represent the computed wave vectors, and the third green arrow is shifted to fit the phase maximums of the background wave. The inconsistent $k_{\mathrm{h}}$ can be different from the two identical $k_{\mathrm{h}}$ in orientation as well as length of $k_{\mathrm{h}}$, but it can also be identical to the two others. This depends on the angles between the three measuring points as explained below. When one examines the wave fronts, the

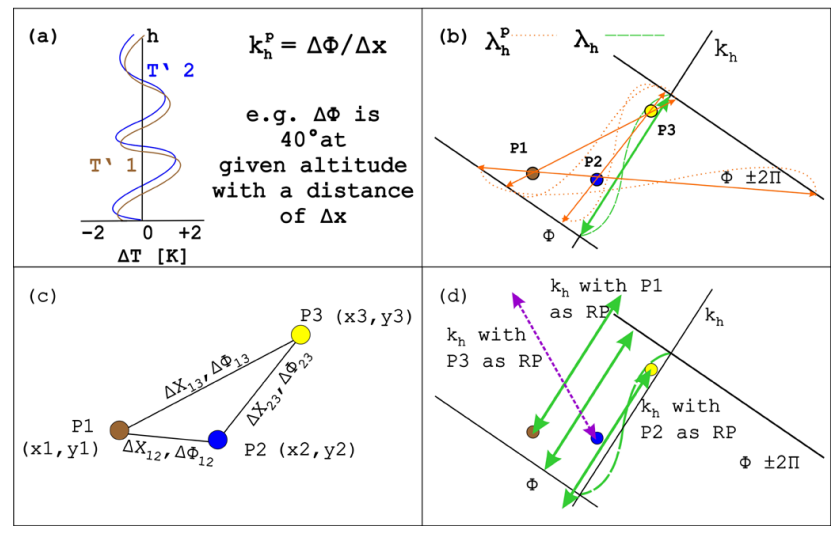

Fig. 2. Displayed are two vertical temperature profiles with a phase shift of $40^{\circ}$ (a), the projected and real horizontal wavelet within 3 points of measurement when the corresponding horizontal wave is known (b), the 3 points of measurement and the well-known parameters (c) and the three possible derived horizontal wave vectors for those 3 points (d). For explanations, see text.

reason for the wrong determination of $k_{\mathrm{h}}$ at one RP becomes clearer. The RP that produces the inconsistent result is placed in between the other two points in relation to the wave fronts.

Another way to treat this problem is with a geometric description as presented in Figs. 3 and 4. Considering the same three points as before, one can represent the intersection of three closely separated RO profiles with a constant altitude plane. The unknown constant successive wave phase lines $\Phi$ and $\Phi \pm 2 \pi$ are illustrated in Fig. 3a. The line of action (line $\mathrm{ab}$ ), as well as the direction of $k$, are obviously also unknown. Now the three possible pairs of points, as shown in Fig. $3 b$, $\mathrm{c}$, and $\mathrm{d}$ are considered. The slope of $k_{\mathrm{h}}$ may be determined, for example in the case shown in Fig. $3 b$, in the following way: from Eq. (2) and the knowledge of both the phase and distance differences between each pair of points, $\lambda_{\mathrm{h}}^{p}$ (black sinusoidal lines) may be determined (Fig. 4a). If we now displace these curves along the blue lines defined by each pair, until we match them with a common extreme (red sinusoidal curves), the opposite extremes of these red curves define the slope of $\Phi$ (line cd). We repeat this procedure in Fig. 4b, observing identical result. In the case of Fig. 4c, note that one of the black curves was displaced in the opposite direction in order to be able to obtain the same slope as in the preceeding two cases. The displacement to the side of the second point (like in the other two cases) would lead to the gray line between points $e$ and $f$ with a slope that does not match the results from the two reference points before (brown and yellow points, Fig. 4a and b). The displacement along the alignment of the blue and brown point leads to the blue line cd, which matches the results from before.

This happens when one of the inner angles, $\alpha, \beta$ or $\gamma$ (in Fig. 3a), is an obtuse angle. If the three angles are acute, no inversion is needed and the three possibilities described, straightforwardly render an identical result. In general - for 


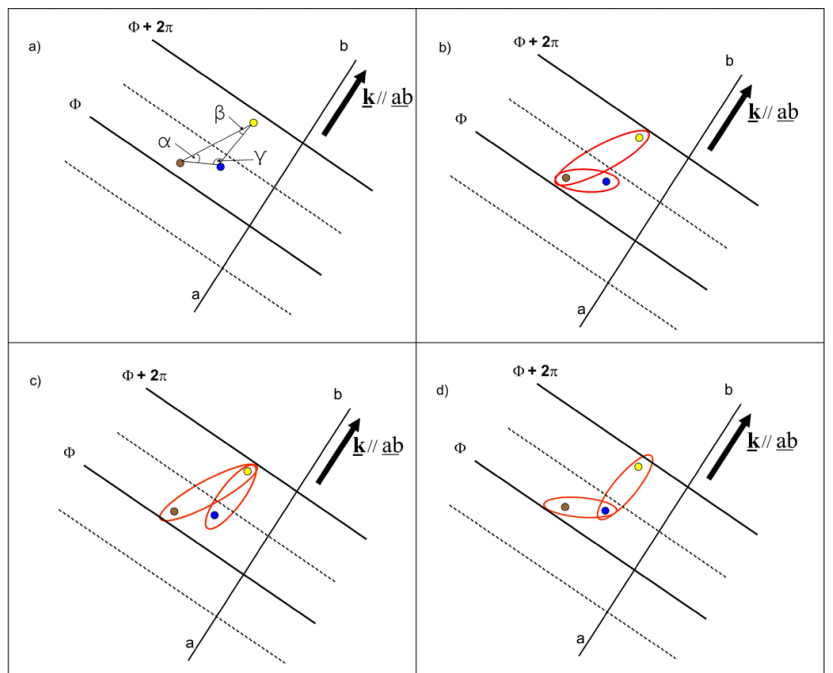

Fig. 3. Part A of the geometrical description of the determination of the real horizontal wavelength. Here the setup of the 3 points (a) and the three possible combinations of solving Eq. (2) for different reference points (b, c and $\mathbf{d}$ ) are displayed.

practical purposes and to handle a huge amount of 3-point groupings - after computing the phase slope as in Fig. 4a to $\mathrm{c}$ for each 3-point grouping, no possible uncertainty remains if we simply consider the prevailing slope (to include 3-point groupings with one inner obtuse angle). $\lambda_{\mathrm{h}}$ is finally illustrated in Fig. $4 \mathrm{a}-\mathrm{c}$ (green curves). When evaluating the phase differences, inconsistencies may arise from wraparound effects. Depending on the reference point, due to the periodicity of the problem, the same phase difference could be regarded, for example, as either very small, or close to $2 \pi$. Furthermore, the inner angle at the reference point must be obtuse in order to allow us to determine a valuable horizontal wavelength. These effects are accounted for by evaluating all possible combinations of a considered group of three points and sorting out the inconsistent combinations.

\section{Sensitivity study}

As mentioned in Sect. 1, the temporal window should be kept as small as possible, while still allowing a sufficient number of 3-point groupings to extract global distributions of the wave parameters. We choose a $2 \mathrm{~h}$ interval. Shorter windows would decrease the number of possible 3-point groupings too much, whereas a larger time window would increase the number of 3-point groupings but would also include profiles from a different wave origin. Another reason for small time windows is that the phase progression caused by wave frequency is an additional error source for the horizontal wavelength determination. Therefore the time window should be much smaller than the wave period. For a closer look, we apply a sensitivity study to Eq. (2), using two sinusoidal curves

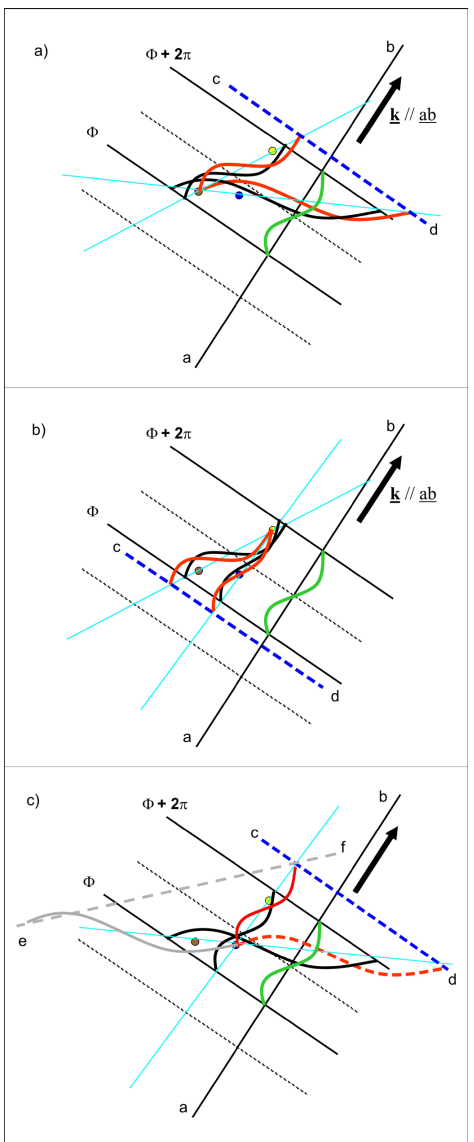

Fig. 4. Part B of the geometrical description of the determination of the real horizontal wavelength. The derived horizontal wavelength for each reference point (the wavelength for part $\mathrm{Ab}$ is displayed in $\mathbf{a}$; the wavelength for part Ac in $\mathbf{b}$; and the wavelength for part Ad in c).

with different phase shifts $\left(0^{\circ}\right.$ and $\left.180^{\circ}\right)$ and four horizontal distances $(100,200,500$ and $1000 \mathrm{~km})$. This only focuses on the one-dimensional case (on $\lambda_{\mathrm{h}}^{p}$ ). With a decreasing phase shift, $\lambda_{\mathrm{h}}$ approaches very high values (Fig. 5). This effect is even stronger when $\Delta x$ increases. A detection of small phase shifts (lower than $30^{\circ}$ ) shows very long wavelengths $\left(\lambda_{\mathrm{h}}^{p} \rightarrow \infty\right)$ for all distances. For larger distances (for example $1000 \mathrm{~km}$ ), a phase shift of $45^{\circ}$ corresponds to a $\lambda_{\mathrm{h}}^{p}$ of more than $10000 \mathrm{~km}$. These long $\lambda_{\mathrm{h}}$ are unrealistic for GWs. This and the fact that alignments cannot be ruled out (small phase shift at a given altitude might be due to the $\pm 2 \pi$ or even $\pm 3 \pi$ periodicity), leading to a limitation of the phase shift. Therefore, we set a lower limit of 0.5 radian $\left(\sim 30^{\circ}\right)$, when the maximum distance is set to be $15^{\circ}$. The new limiting factor must be taken into account when using this method to analyze GPS RO profiles.

Now we examine the impact of the distance dependence for the $\lambda_{\mathrm{h}}$ determination using Eq. (4) (the two-dimensional case). Triads with the spatial interval of $5^{\circ}, 10^{\circ}$ and $15^{\circ}$ were identified. The first and obvious result is that the 


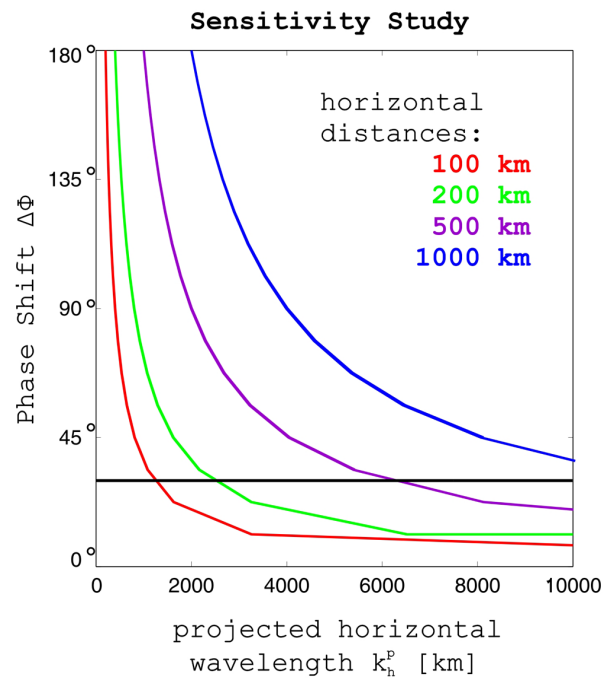

Fig. 5. Sensitivity study for the method introduced by Ern et al. (2004) concerning the resulting wavelength $\left(k_{\mathrm{h}}^{p}\right)$ at different horizontal distances and phase shifts.

shorter the interval, the less 3-point groupings can be found. This was performed for the northern hemisphere $(\mathrm{NH})$ winter $2006 / 2007$ for the altitude range $20-30 \mathrm{~km}$. For $5^{\circ}$ the amount of 3-point groupings is too small for a sufficient statistical global analysis. The results for $10^{\circ}$ and $15^{\circ}$ are shown in Fig. 6. Although the absolute values vary by approximately $50 \%$, the structure of $\lambda_{h}$ is quite similar for both settings. The same effect can be found when studying the results for the MF distribution. A more detailed description of $\lambda_{\mathrm{h}}$ and MF is given in Sect. 6.1. The fact that the horizontal wavelength is strongly dependent on the maximum distance limit shows that the global distribution of gravity wave horizontal wavelengths cannot be reliably determined with the large distances required to obtain sufficient statistics. This method can provide $\lambda_{\mathrm{h}}$ only as an upper boundary due to alignment effects and limitations in the measuring principles and data availability. The $15^{\circ}$ horizontal spacing for the 3 points search was chosen for the global analysis. In addition, the data availability does not allow a global analysis for $\mathrm{NH}$ summer with a $10^{\circ}$ interval.

\section{Comparison 2-point verses 3-point method}

As a reference to ensure that the 3-point method has worked correctly, the results of the horizontal wavelength should always be shorter then those derived by the 2-point method from Ern et al. (2004). For this comparison, the phase shift limitation of $0.5 \mathrm{rad}$ is also applied to the 2-point method. The determined $\lambda_{\mathrm{h}}^{p}$ and the true $\lambda_{\mathrm{h}}$ are shown in Fig. 7a and $\mathrm{b}$ for a $10^{\circ}$ spacing and the $\lambda_{\mathrm{h}}^{p}$ for $\mathrm{a}<300 \mathrm{~km}$ spacing in Fig. 7c. Corresponding to these horizontal wavelengths, the momentum flux, derived using the same spacing and 2-point or 3-point method as before, is displayed in Fig. 7d-f. The results for the horizontal wavelength using the $10^{\circ}$ spacing with the 3-point method are also displayed in Fig. 8a with a different scaling. The chosen scales in both graphics are related to fit the comparability with the other plots in the graphics. First the comparison for the $10^{\circ}$ spacing is discussed (Figs. 7a and b). The detected projected (panel a) and true (panel b) horizontal wavelength clearly show that the 3-point method decreases the horizontal wavelength. The 2-point method delivers wavelengths between 3000 and $5000 \mathrm{~km}$, whereas the 3-point method with the same spacing decreases the detected wavelengths down to values between 1000 and $2000 \mathrm{~km}$. This effect of detecting shorter wavelengths is also found, when the spacing for the 2-point method is decreased to a maximum value of $300 \mathrm{~km}$ (Fig. 7c). The $300 \mathrm{~km}$ limit has been selected because the probability of observing the same wave event increases for spacings shorter than this (McDonald, 2012). Using this $300 \mathrm{~km}$ limit, the projected wavelengths vary within a 1500 to $3500 \mathrm{~km}$ range. The comparison with the horizontal wavelength derived from the 2-point method (Fig. 7a and c) clearly states that even though the spacing of $15^{\circ}$ (as displayed in Fig. 6b) is rather large, the results can match those from the 2-point method or sometimes also provide a detection method for shorter wavelengths than the 2-point method. For the momentum flux, the determined horizontal wavelength plays an important role. The detection of shorter wavelengths leads to higher values in the momentum flux distribution. Therefore the results from the 3-point method (Fig. 7e) show higher values than those of the 2-point method with both spacings $\left(10^{\circ}\right.$ and $<300 \mathrm{~km}$ in Fig. $7 \mathrm{~d}$ and $\mathrm{f}$, respectively).

\section{Global analysis}

For a global analysis, seasonal mean data for JuneAugust 2006 (JJA) and December 2006-February 2007 (DJF) are shown. The altitude range for the statistical analysis is set to $20-30 \mathrm{~km}$. The global distribution of the number of available 3-point groupings and the mean distance within each 3-point grouping are shown in Fig. 8 for the NH summer (panels a and c) and winter (panels b and d) respectively. Figure $8 \mathrm{a}$ and $\mathrm{b}$ show that the number of 3-point groupings are higher in the extratropics than in the Equator region or closer to the poles. As mentioned in Sect. 4, the amount of measurements in the beginning of the COSMIC mission was not as high as expected. By the end of 2006, all six satellites were running, and therefore increasing the number of ROs. For Fig. 8a and b, different scales are chosen to show the structure of the groupings of 3 points for both seasons. The mean distance between the different 3-point groupings (see Fig. $8 \mathrm{c}$ and d) is similar, but the clustering phase at the beginning of the COSMIC mission has a small impact which leads to shorter distances in the $\mathrm{NH}$ summer than winter. These differences are most distinct over Australia and South 

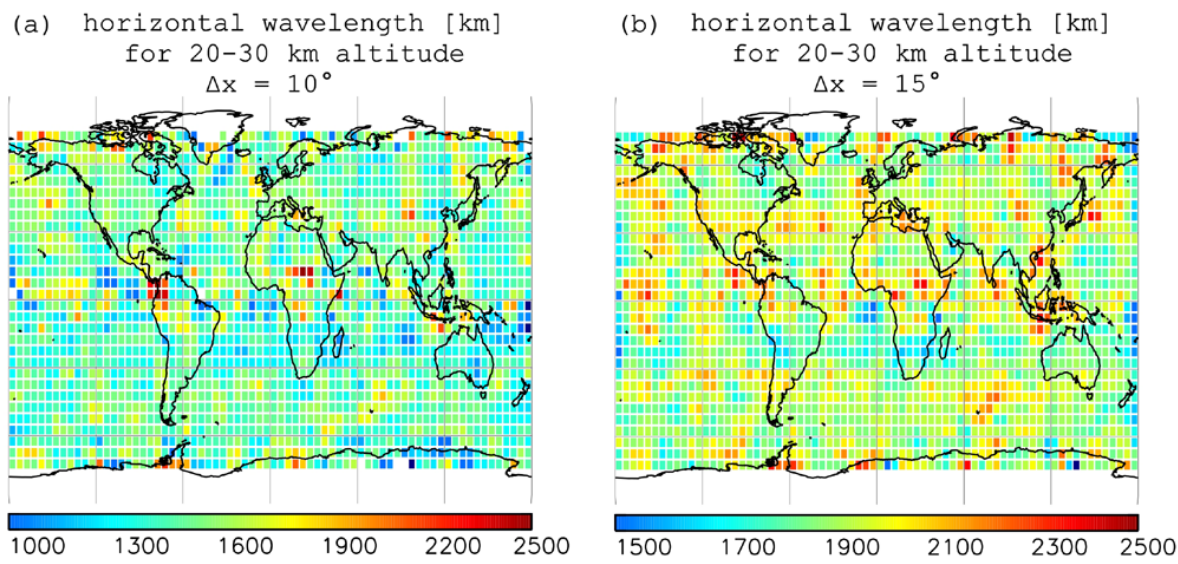

Fig. 6. Horizontal wavelength derived from 3 points of COSMIC RO temperature profiles for the NH winter 2006/2007. Sensitivity of the horizontal wavelength regarding distance in spacing between the 3 points for $10^{\circ}$ (a) and $15^{\circ}$ (b) spatial interval are displayed. Note, that the color scale in (a) and (b) is different.

(a) 2-point method with $10^{\circ}$ spacing

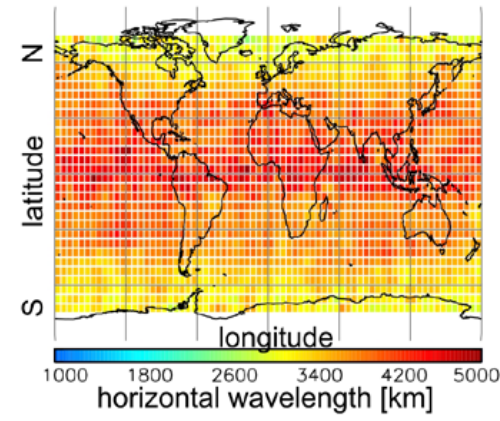

(d)

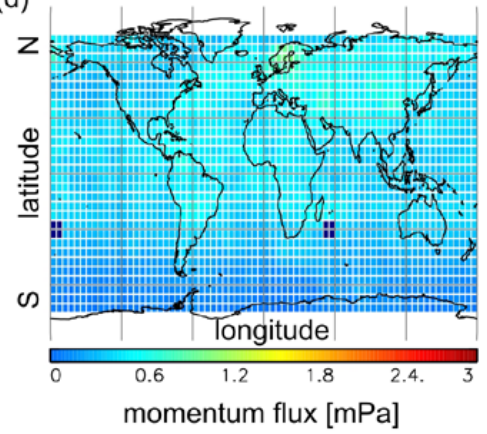

(b)

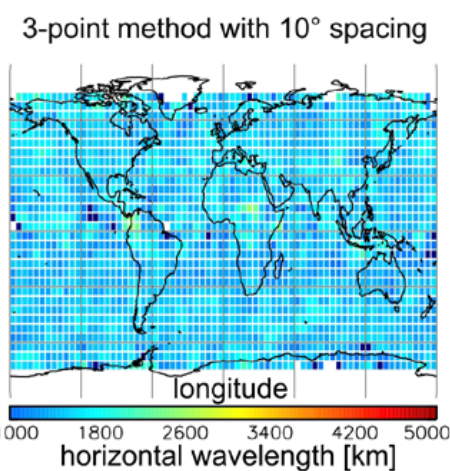

(e)

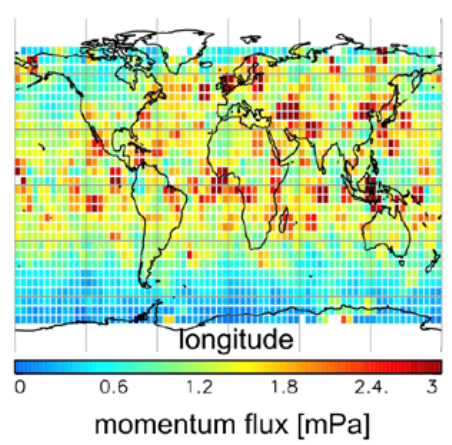

(c) 2-point method with $300 \mathrm{~km}$ spacing

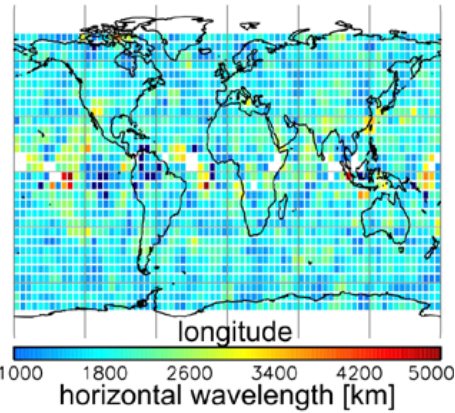

(f)

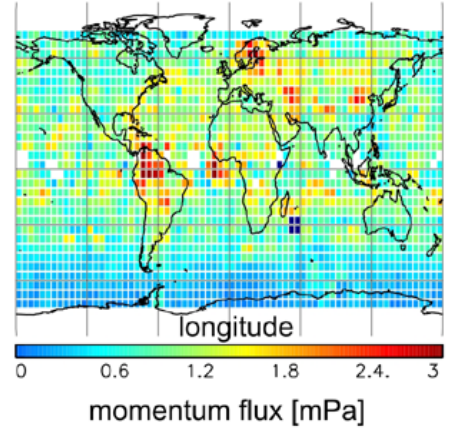

Fig. 7. Horizontal wavelength $\left(k_{\mathrm{h}}^{p}\right)(\mathbf{a}$ and $\mathbf{c})$ and true horizontal wavelength (b) with spacings of $10^{\circ}(\mathbf{a}$ and $\mathbf{b})$ and $<300 \mathrm{~km}(\mathbf{c})$ and the corresponding momentum flux $d-f$.

America. The maximum distance is limited by a $15^{\circ}$ circle, which represents about $1500 \mathrm{~km}$ at the Equator and $500 \mathrm{~km}$ at high latitudes. The gaps in the NH summer are found in all wave parameters. There, the number of 3-point groupings is too small for a statistical analysis. For all wave parameters, as well as for the mean distance, the results for each 3 points (mean $E_{\mathrm{p}}, \lambda_{\mathrm{v}}$ and the computed $\lambda_{\mathrm{h}}$ along with MF) are attributed to their mean lat./long. position (MP) and then fed into a $5^{\circ} \times 5^{\circ}$ lat./long. grid. Due to the low numbers of 3 -point groupings in polar regions (north of $75^{\circ} \mathrm{N}$, south of $75^{\circ} \mathrm{S}$ ), these areas are not evaluated. As mentioned before, a temporal and spatial window is used, and the $\Delta \Phi$ limitation and the comparison of the dominant $\lambda_{\mathrm{V}}$ eliminate about $30 \%$ of all measured 3-point groupings.

Figure $9 \mathrm{a}$ and $\mathrm{b}$ display the $\lambda_{\mathrm{V}}$ distributions for NH summer (panel a) and winter (panel b) with minimum values of 

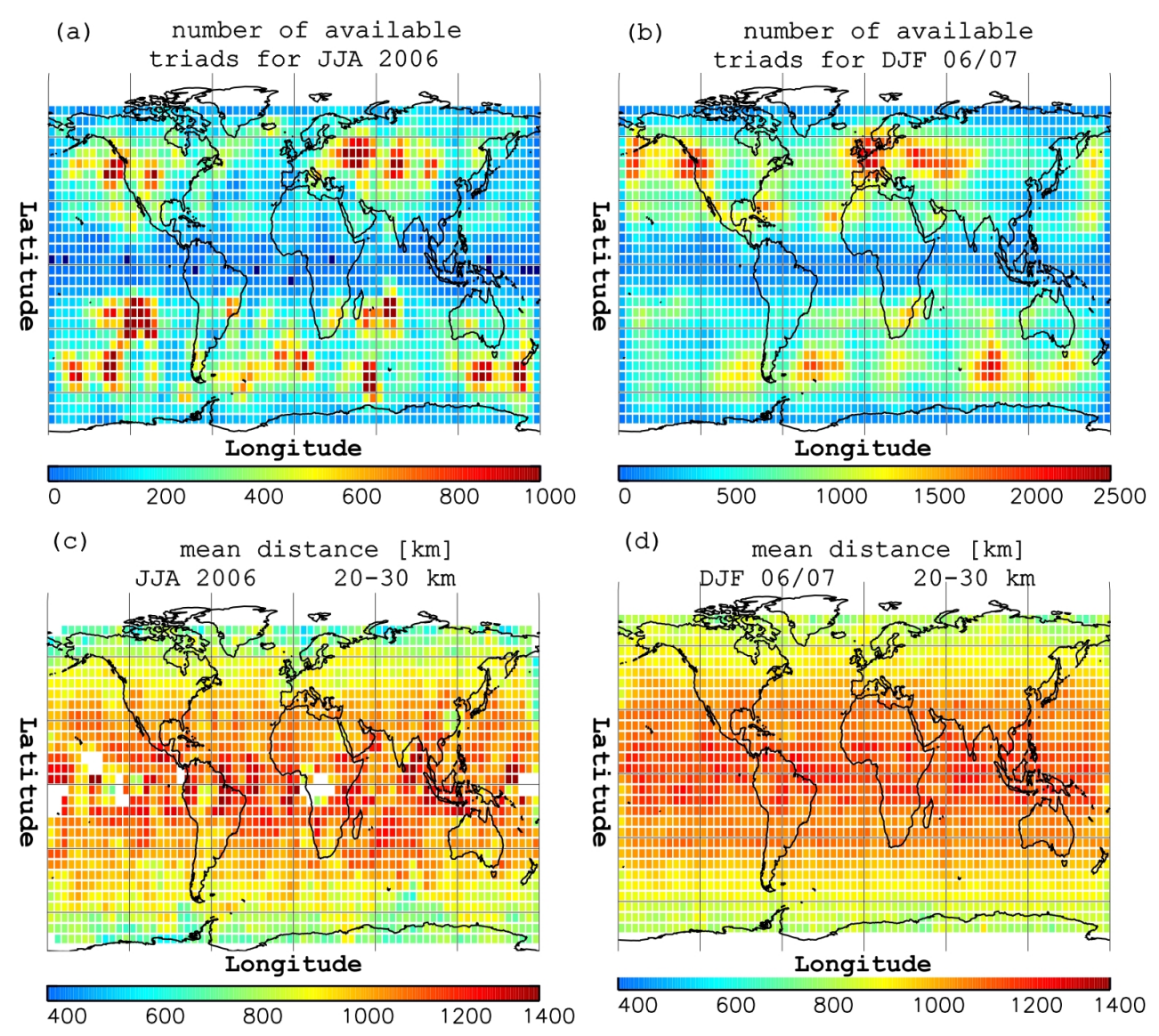

Fig. 8. Number of 3-point groupings from COSMIC for JJA 2006 (a) and DJF 2006/2007 (b) and the mean horizontal distance of the three single profiles within each 3-point grouping (e and f) for the altitude range of $20-30 \mathrm{~km}$.

$5 \mathrm{~km}$ around the Equator and up to $10 \mathrm{~km}$ in the extratropics and polewards. At first glance, a small general decrease of $\lambda_{\mathrm{V}}$ from Fig. 9a to $\mathrm{b}$ can be seen. Taking a closer look, some significant changes in both directions are detectable for example, the decrease of $\lambda_{\mathrm{v}}$ from about $9 \mathrm{~km}$ to less than $7 \mathrm{~km}$ over Canada and the US, as well as over Russia, or the increase of $\lambda_{\mathrm{V}}$ over Australia and northern Africa. All these changes are located over land, but there is also a decrease in the $\lambda_{\mathrm{V}}$ over the southern hemisphere (SH) water regions, which is most significant around the Antarctic Peninsula.

The $E_{\mathrm{p}}$ distribution (see Fig. 9c and d) agrees with previous results (Schmidt et al., 2008). Differences in the absolute values come from the different definitions of $E_{\mathrm{p}}$ with the mean $E_{\mathrm{p}}$ for Schmidt et al. (2008) and the peak $E_{\mathrm{p}}$ defined using the GW amplitude in Fig. $9 \mathrm{c}$ and d. The higher values (up to $8 \mathrm{~J} \mathrm{~kg}^{-1}$ ) for both seasons are located along the Equator and decrease towards the polar regions. However, for June-August 2006 the higher values in the extratropics are located on the $\mathrm{SH}$, with particularly high values along the east side of the Andes mountains, mainly due to low-level westerlies and the permanent jet (Alexander and de la Torre, 2010). For December 2006-February 2007, higher values are found in the NH. Going from west to east, the increase in $E_{\mathrm{p}}$ in the $\mathrm{NH}$ can be explained by the various mountain chains and wind shear conditions. East of North America, and in the northeast of Russia, the NH winter weather conditions provide strong wind shear. In northern Europe, the prevailing westerlies induces GWs on the lee side of the Scandinavian mountains with values of up to $8 \mathrm{~J} \mathrm{~kg}^{-1}$. The subtropical jet stream induces high values of $E_{\mathrm{p}}$ when crossing the $\mathrm{Za}$ gros Mountains (Farajzadeh et al., 2011). For both seasons, the Equator region shows high $E_{\mathrm{p}}$ values around $6 \mathrm{~J} \mathrm{~kg}^{-1}$. These values are due to the high amount of convective potential from high temperatures and humidity in that area.

\subsection{Horizontal wavelength}

The $\lambda_{\mathrm{h}}$ distributions (see Fig. 10a for JJA and Fig. 10b for DJF) show a trend of increasing $\lambda_{h}$ towards the Equator. The reason that the $\lambda_{\mathrm{h}}$ scale has a different starting point is that the visibility of the pattern requires different scales for each graphic. This kind of pattern has already been shown by Fröhlich et al. (2007), who used a theoretical $\lambda_{\mathrm{h}}$, and by Wang and Alexander (2010) using GPS RO data. Also, the $\lambda_{h}$ distribution shows longer $\lambda_{h}$ over water in the winter 

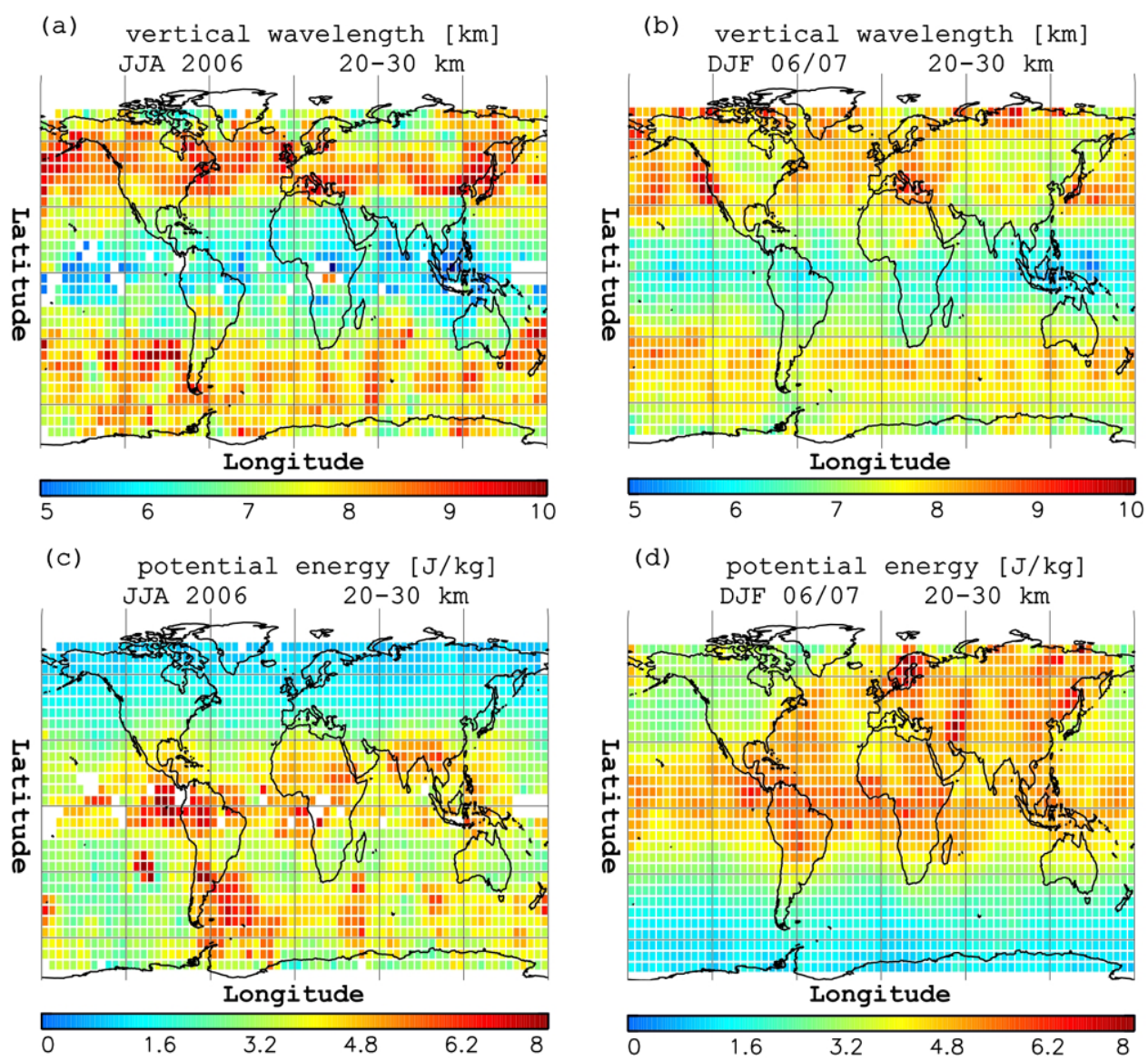

Fig. 9. Vertical wavelength derived from COSMIC for the available 3-point groupings (JJA 2006) (a) and (DJF 2006/07) (b), and the mean potential energy distribution for each season (c and $\mathbf{d}$ ) for the altitude range of $20-30 \mathrm{~km}$.

hemisphere than in the summer hemisphere and decreasing $\lambda_{h}$ over the winter-hemisphere land areas compared to the same regions in summer. The effect of shorter wavelength over land is most significant for the SH winter (Fig. 10a). The absolute value of $\lambda_{\mathrm{h}}$ at the east of the Andes is higher than the results from de la Torre and Alexander (2005), but the derived $\lambda_{\mathrm{h}}$ here is only an upper boundary of $\lambda_{\mathrm{h}}$ (see Sect. 4). The $\lambda_{\mathrm{h}}$ would decease by a mean of $50 \%$ when changing the spatial window from $15^{\circ}$ to $10^{\circ}$. Since there is also a small correlation between the mean distance distribution of the 3-point groupings and the derived horizontal wavelengths, the discussed variations might be influenced by the sampling method.

\subsection{Momentum flux}

The global MF distribution is displayed in Figs. 10c and d for JJA and DJF, respectively. The absolute values of MF range between 0 and $3 \mathrm{mPa}$, but the pattern of the distribution is more crucial for the evaluation. The absolute values depend on the derived $\lambda_{\mathrm{h}}$ and therefore also on the chosen spatial interval. For the MF, however, the absolute values increase when choosing a shorter spatial window, but the pattern does not change significantly. For both seasonal mean MF distributions (JJA and DJF), a band of high values is located along the Equator. In addition, the winter hemisphere shows more wave activity (higher MF values) than the summer hemisphere. The higher values are found at the east of the Andes mountains and along the Antarctic Peninsula during the SH winter (Fig. 10c) and at the east on the Scandinavian Mountains and the Zagros Mountains (Iran) during the NH winter (Fig. 10d).

MF was derived from model data and satellite measurements were performed by Geller et al. (2013). Other global distributions of the MF were given, e.g., by Ern et al. (2004, 2011), Fröhlich et al. (2007), and Wang and Alexander (2010). Again, the absolute values shall not be compared even though the range is 0 to $3 \mathrm{mPa}$ which fits to the results derived by Ern et al. (2004) and Fröhlich et al. (2007). But the general patterns fit each other as well. Not all results are presented for both seasons and for that exact time period; therefore the patterns can also differ. Nevertheless, all results show higher values for MF in the winter hemisphere. Wang and Alexander (2010) also show the two areas with 

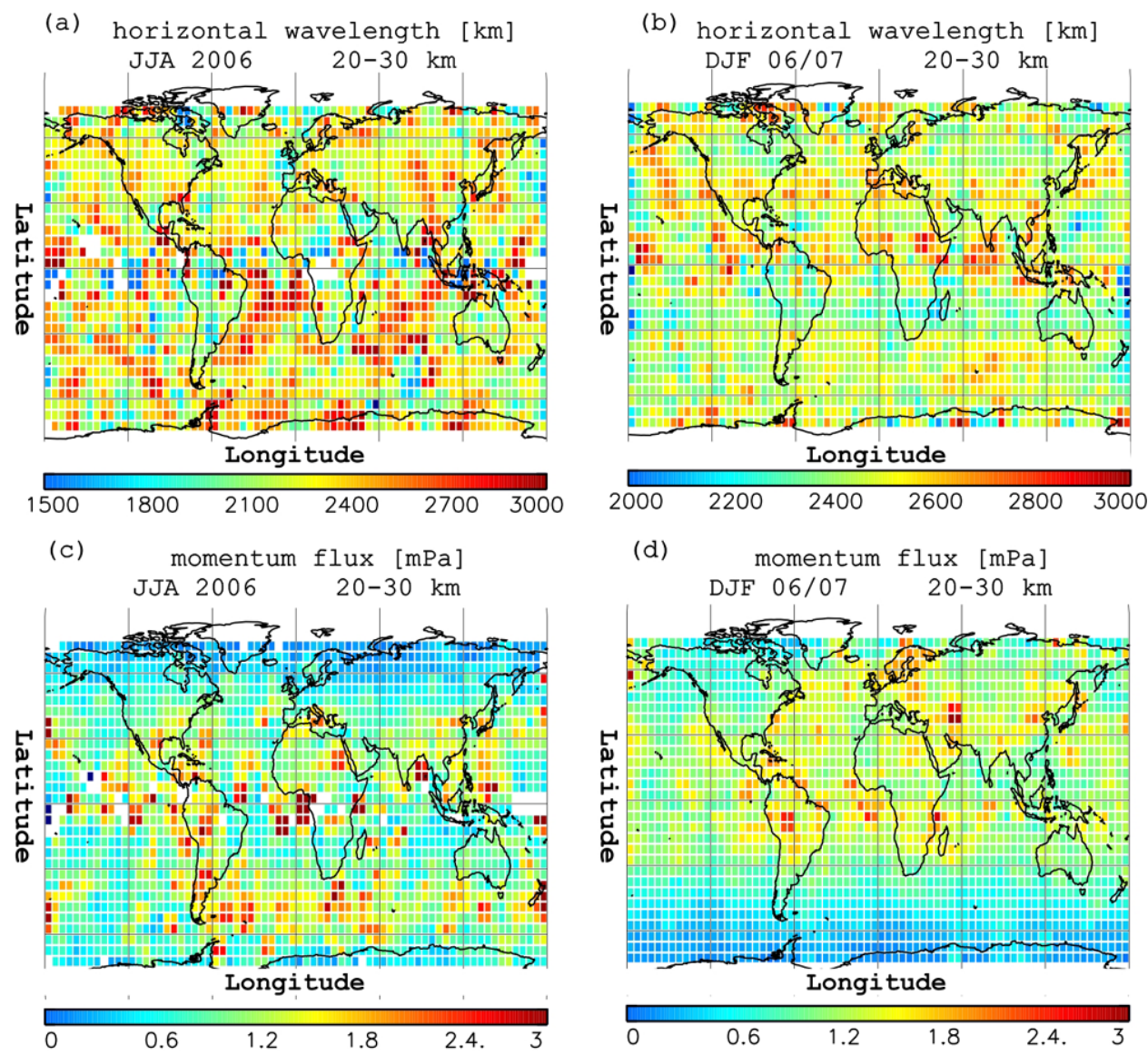

Fig. 10. Horizontal wavelength derived from 3 points of COSMIC temperature profiles for the available 3 points (JJA 2006) (a) and (DJF 2006/07) (b), and the mean momentum flux distribution respectively for each season (c and d) for the altitude range of 20-30 km.

high values of MF, one over South America, the other over Africa, for the same time period (DJF), and the high MF over Scandinavia. The method of taking 3 points instead of a fixed $15^{\circ} \times 15^{\circ}$ grid allows for a higher resolution in the final distributions of the derived wave parameters.

\section{Conclusions}

This study provides information about the determination of momentum flux using three co-located RO profiles. COSMIC data from the clustering phase (April 2006February 2007) were analyzed. Some of the limitations applied come from the method introduced by Ern et al. (2004) (small temporal and spatial windows, analysis for each altitude); others were added to minimize the alignment effects $\left(\lambda_{\mathrm{v}}, \Delta \Phi\right.$ and $\left.E_{\mathrm{p}}\right)$. Global distributions of the vertical, horizontal wavelengths as well as potential energy and MF as seasonal means in the altitude range 20 to $30 \mathrm{~km}$, from JuneAugust 2006 and December 2006-February 2007 are displayed as an example of our studies. Wang and Alexander (2010) concluded that the data density is rather too coarse for an accurate determination of the horizontal wave parameters.
This work optimizes the approach of Wang and Alexander (2010), leading to results with a higher resolution. The new applied phase shift limitation and the restrictions in the geometric constellation of the 3-point groupings considered lead to a higher resolution in the results than Wang and Alexander (2010) showed. However, a disadvantage of this method is the high dependency of $\lambda_{\mathrm{h}}$ on the spacing within the 3 points. After the clustering phase of the six COSMIC satellites, the occultations were further apart, making it harder to find suitable 3-point groupings. However, the method can be applied to other vertical temperature measurements, as long as they provide the required spatial and temporal resolution.

Acknowledgements. Thanks to UCAR for providing the COSMIC data. P. Llamedo and A. de la Torre are members of CONICET under grant 5932.

The service charges for this open access publication have been covered by a Research Center of the Helmholtz Association.

Edited by: S. Slijkhuis 


\section{References}

Alexander, M. J., Geller, M., McLandress, C., Polavarapu, S., Preusse, P., Sassi, F., Sato, K., Eckermann, S., Ern, M., Herzog, A., Kawatani, Y., Pulido, M., Shaw, T. A., Sigmond, M., Vincent, R., and Watanabe, S.: Recent developments in gavity-wave effects in climate models and the global distribution of gravitywave momentum flux from observations and models, Q. J. Roy. Meteorol. Soc., 136, 1103-1124, doi:10.1002/qj.637, 2010.

Alexander, P. and de la Torre, A.: A Method to Infer Three Cartesian Wavelength of a Mountain Wave from Three Soundings, Am. Meteorol. Soc. Notes and Correspondence, 49, 2069-2074, doi:10.1175/2010JAMC2348.1, 2010.

Alexander, P., de la Torre, A., and Llamedo, P.: Interpretation of gravity wave signatures in GPS radio occultations, J. Geophys. Res., 113, D16117, doi:10.1029/2007JD009390, 2008a.

Alexander, S. P., Tsuda, T., and Kawatani, Y.: COSMIC GPS Observations of the Northern Hemisphere winter stratospheric gravity waves and comparisons with an atmospheric general circulation model, Geophys. Res. Lett., 35, L10808, doi:10.1029/2008GL033174, 2008b.

Anthes, R. A., Bernhardt, P. A., Chen, Y., Cucurull, L., Dymond, K. F., Ector, D., Healy, S. B., Ho, S.-P., Hunt, D. C., Kuo, Y.-H., Liu, H., Manning, K., Mccormick, C., Meehan, T. K., Randel, W. J., Rocken, C., Schreiner, W. S., Sokolovskiy, S. V., Syndergaard, S., Thompson, D. C., Trenberth, K. E., Wee, T.-K., Yen, N. L., and Zen, Z.: The COSMIC/Formosat-3 Mission Early Results, Am. Meteorol. Soc., 89, 313-333, doi:10.1175/BAMS-89-3-313, 2008.

Baumgaertner, A. J. G. and McDonald, A. J.: A gravity wave climatology for Antarctica compiled from Challenging Minisatellite Payload/Global Positioning System (CHAMP/GPS) radio occultations, J. Geophys. Res., 112, D05103, doi:10.1029/2006JD007504, 2007.

de la Torre, A. and Alexander, P.: Gravity waves above Andes detected from GPS radio occultation temperature profiles: Mountain forcing?, Geophys. Res. Lett., 32, L17815, doi:10.1029/2005GL022959, 2005.

de la Torre, A., Schmidt, T., and Wickert, J.: A global analysis of wave potential energy in the lower stratosphere derived from 5 years of GPS radio occultation data with CHAMP, Geophys. Res. Lett., 33, L24809, doi:10.1029/2006GL027696, 2006a.

de la Torre, A., Alexander, P., Llamedo, P., Menendez, C., Schmidt, T., and Wickert, J.: Gravity waves above the Andes detected from GPS radio occultation temperature profiles: Jet mechanism?, Geophys. Res. Lett., 33, L248010, doi:10.1029/2006GL027343, 2006b.

Eckermann, S. D., Wu, D. L., Doyle, J. D., Burris, J. F., McGee, T. J., Hostetler, C. A., Coy, L., Lawrence, B. N., Stephens, A., McCormack, J. P., and Hogan, T. F.: Imaging gravity waves in lower stratospheric AMSU-A radiances, Part 2: Validation case study, Atmos. Chem. Phys., 6, 3343-3362, doi:10.5194/acp-63343-2006, 2006.

Ern, M., Preusse, P., Alexander, M. J., and Warner, C. D.: Absolute values of gravity wave momentum flux derived from satellite data, J. Geophys. Res., 109, D20103, doi:10.1029/2004JD004752, 2004.

Ern, M., Preusse, P., Gille, J. C., Hepplewhite, C. L., Mlynczak, M. G., Russel III, J. M., and Riese, M.: Implications for atmospheric dynamics derived from global observations of gravity wave mo- mentum flux in stratosphere and mesosphere, J. Geophys. Res., 116, D19107, doi:10.1029/2011JD015821, 2011.

Farajzadeh, M., Khorany, A., and Lashkary, H.: The Relation Between Jet Stream Location and Cyclones Over the Western Iran, Am. J. Appl. Sci., 5, 1308-1312, doi:10.3844/ajassp.2008.1308.1312, 2008.

Fritts, D. C. and Alexander, M. J.: Gravity wave dynamics and effects in the middle atmosphere, Rev. Geophys., 41, 1003, doi:10.1029/2001RG000106, 2003.

Fröhlich, K., Schmidt, T., Ern, M., Preusse, P., de la Torre, A., Wickert, J., and Jacobi, Ch.: The global distribution of gravity wave energy in the lower stratosphere derived from GPS data and gravity wave modelling: Attempt and challenges, J. Atmos. Sol.-Terr. Phy., 69, 2238-2248, doi:10.1016/j.jastp.2007.07.005, 2007.

Geller, M. A., Alexander, M. J., Love, P. T., Bacmeister, J., Ern, M., Hertzog, A., Manzini, E., Preusse, P., Sato, K., Scaife, A., and Zhou, T.: A comparison between gravity wave momentum fluxes in observations and climate models, J. Climate, 26, 6383-6405, doi:10.1175/JCLI-D-12-00545.1, 2013.

Hocke, K. and Tsuda, T.: Gravity Waves and Ionospheric Irregularities over Tropical Convection Zones observed by GPS/MET Radio Occultation, Geophys. Res. Lett., 28, 28152818, doi:10.1029/2001GL013076, 2001.

Hoffmann, L. and Alexander, M. J.: Retrieval of stratospheric temperatures from Atmospheric Infrared Sounder radiance measurements for gravity wave studies, J. Geophys. Res., 114, D07105, doi:10.1029/2008JD011241, 2009.

Holton, J. R., Alexander, M. J., and Boehm, M. T.: Evidence for short vertical wavelength Kelvin waves in the Department of Energy-Atmospheric Radiation Measurements Nauru99 radiosonde data, J. Geophys. Res., 106, 20125-20129, doi:10.1029/2001JD900108, 2001.

Horinouchi, T. and Tsuda, T.: Spatial structures and statistics of atmospheric gravity waves derived using a heuristic vertical crosssection extraction from COSMIC GPS radio occultation data, J. Geophys. Res., 114, D16110, doi:10.1029/2008JD011068, 2009.

Kuo, Y.-H., Sokolovskiy, S., Anthes, R. A., and Vandenberghe, F.: Assimilation of GPS Radio Occultation Data for Numerical Weather Prediction, Terr. Atmos. Ocean. Sci., 11, 157-186, 2000.

Kursinski, E. R., Hajj, G. A., Schofield, J. T., Linfiled, R. P., and Hardy, K. R.: Observing Earth's atmosphere with radio occultation measurements using the Global Positioning System, J. Geophys. Res., 102, 23429-23465, doi:10.1029/97JD01569, 1997.

Lin, L., Zou, X., Anthes, R., and Kuo, Y.-H.: COSMIC GPS Radio Occultation Temperature Profiles in Clouds, Am. Meteorol. Soc. MWR, 138, 1104-1118, doi:10.1175/2009MWR2986.1, 2010.

Marquardt, C. and Healy, S. B.: Measurement Noise and Stratospheric Gravity Wave Characteristics obtained from GPS Occultation Data, J. Meteorol. Soc. Jpn., 83, 417-428, 2005.

McDonald, A. J.: Gravity wave occurence statistics derived from paired COSMIC/FORMOSAT-3 observations, J. Geophys. Res. 117, D15106, doi:10.1029/2011JD016715, 2012.

Nappo, C. J.: An Introduction to Atmospheric Gravity Waves, Academic Press Inc, International Geophysics Series, Vol. 85, 2002.

Preusse, P., Schroeder, S., Hoffmann, L., Ern, M., Friedl-Vallon, F., Ungermann, J., Oelhaf, H., Fischer, H., and Riese, M.: New perspectives on gravity wave remote sensing by space- 
borne infrared limb imaging, Atmos. Meas. Tech., 2, 299-311, doi:10.5194/amt-2-299-2009, 2009.

Schmidt, T., de la Torre, A., and Wickert, J.: Global gravity wave activity in the tropopause region from CHAMP radio occultation data, Geophys. Res. Lett., 35, L16807, doi:10.1029/2008GL034986, 2008.

Sutherland, B. R.: Internal Gravity Waves, Cambridge University Press, 2010.

Tsuda, T., Nishida, M., Rocken, C., and Ware, R. H.: A global morphology of gravity wave activity in the stratosphere revealed by the GPS occultation data (GPS/MET), J. Geophys. Res., 105, 7257-7273, doi:10.1029/1999JD901005, 2000.

Tsuda, T., Ratnam, M. V., May, P. T., Alexander, M. J., Vincent, R. A., and MacKinnon, A.: Characteristics of gravity waves with short vertical wavelengths observed with radiosonde and GPS occultation during DAWEX (Darwin Area Wave Experiment), J. Geophys. Res., 109, D20S03, doi:10.1029/2004JD004946, 2004.

Wang, L. and Alexander, M. J.: Gravity Wave activity during stratospheric sudden warmings in the 2007-2008 Northern Hemisphere winter, J. Geophys. Res., 114, D18108, doi:10.1029/2009JD011867, 2009.
Wang, L. and Alexander, M. J.: Global Estimates of Gravity Wave Parameters from GPS Radio Occultaton Temperature Data, J. Geophys. Res., 115, D21122, doi:10.1029/2010JD013860, 2010.

Wickert, J.: Das CHAMP-Radiookkultationsexperiment: Algorithmen, Prozessierungssystem und erste Ergebnisse, Sci. Tech. Report, STR 0207, GFZ, Potsdam, available at: http:// gfzpublic.gfz-potsdam.de/pubman/item/escidoc:8575:5 (last access: 18 November 2013), 2002.

Wicker, J., Reigberg, C., Beyerle, G., König, R., Marquardt, C., Schmidt, T., Grunwaldt, L., Meehan, T. K., Melbourne, W. G., and Hocke, K.: Atmosphere sounding by GPS radio occultation: First results from CHAMP, Geophys. Res. Lett., 28, 3263-3266, doi:10.1029/2001GL013117, 2001.

Wright, C. J., Rivas, M. B., and Gille, J. C.: Intercomparisons of HIRDLS, COSMIC and SABER for the detection of stratospheric gravity waves, Atmos. Meas. Tech., 4, 1581-1591, doi:10.5194/amt-4-1581-2011, 2011. 